\title{
Effects of Spray-Drying and Freeze-Drying on Bioactive and Volatile Compounds of Smoke Powder Food Flavouring
}

\author{
Xing Xin ${ }^{1} \cdot$ Sinemobong Essien ${ }^{1} \cdot$ Kiri Dell $^{2} \cdot$ Meng Wai Woo $^{1} \cdot$ Saeid Baroutian $^{1}$ (I)
}

Received: 26 August 2021 / Accepted: 4 February 2022 / Published online: 23 February 2022

(c) The Author(s) 2022

\begin{abstract}
Transforming liquid smoke to powder form can provide convenience for use and storage. Liquid smoke was prepared by fast pyrolysis technology using a fluidised bed and converted to smoke powder by spray-drying or freeze-drying processes. Both drying processes effectively retained the bioactive compounds in the powder encapsulates with retention efficiencies up to $80 \%$. The bioactive capacities were approximately two times higher than liquid smoke. Spray-drying did not induce thermal damage to the bioactive compounds, and the dominant compounds were retained in the powders. Gas chromatography-mass spectrometry and principal component analysis indicated that the chemical composition was not significantly changed after both drying methods, but small molecular carbonyls, furans and phenols were partially lost. The spray-dried particles had a spherical shape, while freeze-dried particles had irregular shapes because of different powder preparation methods. The particle size of spray-dried powders was in the range of 6.3 to $6.9 \mu \mathrm{m}$, while the value for freeze-dried powders was decreased from 580.4 to $134.7 \mu \mathrm{m}$ by increasing the maltodextrin concentration. The freeze-dried powders performed better in terms of flowability and cohesiveness because of their relatively high density and large particle size. This study revealed that both encapsulation methods could efficiently prepare smoke powder. Spray-drying process would be suitable for large-scale production, while freeze-drying could be used to optimize the encapsulation efficiency of bioactive compounds.
\end{abstract}

Keywords Bioactive $\cdot$ Smoke flavouring $\cdot$ Principal component analysis $\cdot$ Spray-drying $\cdot$ Freeze-drying $\cdot$ Encapsulation

\section{Introduction}

Liquid smoke is a smoke flavouring food ingredient that can increase the food shelf life (Dimakopoulou-Papazoglou \& Katsanidis, 2017). Compared with traditional food smoking, food treatment with liquid smoke is fast, safe and environmental-friendly (Arvanitoyannis \& Kotsanopoulos, 2012; Šimko, 2005). Liquid smoke is usually prepared by smouldering, a slow process by burning wood with limited oxygen. Alternatively, fast pyrolysis can rapidly and efficiently convert wood into liquid smoke at an inert atmosphere (Xin et al., 2020). Fast-pyrolysis prepared liquid smoke showed a high antioxidant capacity and an equivalent safety level to commercialised liquid smoke (Xin et al., 2021). Liquid

Saeid Baroutian

s.baroutian@auckland.ac.nz

1 Department of Chemical and Materials Engineering, The University of Auckland, Auckland, New Zealand

2 Faculty of Business and Economics, The University of Auckland, Auckland, New Zealand smoke is primarily composed of organic acids, carbonyls, phenols, furans and furfurals (Xin et al., 2020). A complex mixture of these bioactive compounds contributes to the organoleptic, colouring, antimicrobial and antioxidant effects on treated food (Maga, 2018). These bioactive compounds are sensitive to light, high temperatures and oxygen (Taruna Syah et al., 2016). Spray-drying or freeze-drying can encapsulate the bioactive compounds from liquid smoke to increase their stability and avoid undesirable interactions with other compounds. In addition, a solid product is more convenient for use and storage when compared to the original liquid of the product.

Spray-drying can encapsulate plant-based bioactive compounds, including liquid smoke (Belščak-Cvitanović et al., 2015). Ariestya et al. (2016) spray-dried coconut shell liquid smoke and applied the encapsulates to preserve tilapia fish meat. The results showed that the smoke powder inhibited microbial growth and maintained the quality of the fish meat throughout nine-day cold storage. Taruna Syah et al. (2016) investigated the impacts of spray-drying process conditions on the produced smoke microcapsules. The increased encapsulant 
concentration and spray-drying inlet temperature improved the microcapsules' product yield, phenol retention and solubility. Saloko et al. (2014) prepared smoke microcapsules derived from coconut shells for application on tuna fish. These smoke microcapsules had high values of total phenolic content, total acid content and radical scavenging activity. The smoke microcapsules were sufficient to maintain the freshness of the tuna fish meat for $48 \mathrm{~h}$ at room temperature.

Freeze-drying is a common method to encapsulate heatsensitive bioactive compounds (Celli et al., 2015). To the best of our knowledge, there are no data about the freezedrying of liquid smoke. Freeze-drying had been used to encapsulate red wine (Sanchez et al., 2013), sumac extract (Caliskan \& Dirim, 2016) and acerola plum (Rezende et al., 2018). A previous study showed freeze-dried powders had better flowability, wettability and solubility, while spraydried powders presented less moisture content and water activity values (Rezende et al., 2018).

To the best of our knowledge, there is limited information about the freeze-drying of liquid smoke. It is unclear whether spray-drying or freeze-drying better encapsulates the bioactive compounds or produces better smoke powder products. Spray-drying is an efficient process that is simple, scalable and low cost. However, the high processing temperatures can quickly damage active ingredients. Freeze-drying is particularly suitable for drying heat-sensitive materials (Desai \& Jin Park, 2005). Compared with spray-drying, it often results in greater product uniformity and better stability. In this study, liquid smoke produced by the fast pyrolysis process was encapsulated by spray-drying and freeze-drying. The process yield, bioactive properties, chemical composition and physical properties were investigated. The effects of drying processes on encapsulation performance could be of significant interest to food ingredient research and the industry.

\section{Materials and Methods}

\section{Materials}

Kanuka woodchips were obtained from the East Cape of New Zealand and used for liquid smoke production. Kanuka (Kunzea ericoides) is a native tea tree species in New Zealand and is commonly used for food smoking (Essien et al., 2019). Maltodextrin was used as the encapsulation carrier, purchased from Bulk Powders New Zealand. Chemicals and standards used in this study were purchased from Sigma-Aldrich (New Zealand), including gallic acid, catechin hydrate, Folin-Ciocalteu's phenol reagent, DPPH (1, 1-diphenyl-2-picrylhydrazyl), Trolox (6-hydroxy-2,-5,-7,-8-tetramethylchroman-2-carboxylic acid), aluminium chloride, sodium carbonate, sodium nitrite and GC-grade dichloromethane.

\section{Liquid Smoke Production and Encapsulation}

Kanuka woodchips were fast-pyrolysed at $450{ }^{\circ} \mathrm{C}$ in a fluidised-bed reactor to prepare liquid smoke. The details of the reactor are illustrated in a previous study (Xin et al., 2021). The process produced liquid smoke with a yield of $30 \mathrm{wt} \%$ and valuable by-products, biochar and pyrolysis oil, with yields of 24 and $18 \mathrm{wt} \%$. The prepared liquid smoke was an aqueous phase liquid with a brown to red colour. Maltodextrin was diluted in the fast pyrolysis liquid smoke to prepare the feed solutions for spray-drying and freeze-drying. Three feed solutions were prepared at ratios of 6:1, 5:1 and 4:1 (liquid smoke/maltodextrin, $\mathrm{w} / \mathrm{w})$.

Spray-drying of each feed solution was achieved in a Büchi B-290 spray dryer (Maia et al., 2019). Spray-drying process was maintained at an air inlet temperature of $150{ }^{\circ} \mathrm{C}$, aspirator rate of $100 \%$, atomising gas flowrate of $11.1 \mathrm{~L} / \mathrm{min}$ (standard temperature and pressure) and feeding pump rate of $10 \%$. The outlet temperature was in the range of $60-80^{\circ} \mathrm{C}$. Spray-dried products from the cyclone container and drying chamber were collected and weighed. The three powder products were labelled as SPD-6/1, SPD-5/1 and SPD-4/1, respectively, corresponding to the three feed solution ratios of $6: 1,5: 1$ and $4: 1$.

Freeze-drying of each feed solution was achieved using a Christ Alpha 1-2 LDplus freeze dryer (Condurache et al., 2019). The three solutions were frozen at $-18{ }^{\circ} \mathrm{C}$ for $48 \mathrm{~h}$ before placing in the freeze-dryer chamber. The process conditions were a condenser temperature of $-58.8^{\circ} \mathrm{C}$, a pressure of 6.11 mbar, a vacuum of 0.42 mbar and a drying time of $48 \mathrm{~h}$. After freeze-drying, the glass-like samples were ground using a mortar and pestle following a previous study (Rezende et al., 2018). The three powder products labelled as FZD-6/1, FZD-5/1 and FZD-4/1, respectively, corresponding to the three feed solution ratios of $6: 1,5: 1$ and $4: 1$.

Six smoke powder samples were obtained from spray and freeze-drying and stored in a desiccator at around $20{ }^{\circ} \mathrm{C}$ until the analysis in the following 4 weeks. Spraydried powders had a yellow colour like butter, while freeze-dried ones had a brown colour like chocolate.

The product yield is calculated according to Eq. (1):

$\mathrm{Y}_{\text {product }}=\frac{\mathrm{M}_{\text {powder }}}{\mathrm{M}_{\mathrm{TSS}}} \times 100$

where $\mathrm{Y}_{\text {product }}$ is the yield of powder product (wt. \%), $\mathrm{M}_{\text {powder }}$ is the mass of obtained powder product and $\mathrm{M}_{\mathrm{TSS}}$ is the mass of total soluble solid in the feed solution. 


\section{Determination of Bioactive Activities}

The smoke powder products and kanuka liquid smoke were dissolved and diluted in distilled water to $10 \mathrm{mg} /$ $\mathrm{mL}$. These solutions were analysed for total phenolic content (TPC), total flavonoid content (TFC), ferric reducing antioxidant power assay (FRAP) and DPPH scavenging activity (DPPH) using an ultraviolet-visible (UV) microplate reader (EnSpire 2300, PerkinElmer).

Total phenolic content (TPC) was determined by the Folin-Ciocalteu assay by following a previous study (Munir et al., 2018). The solutions $(0.025 \mathrm{~mL})$ and gallic acid standards were mixed with $0.125 \mathrm{~mL}$ of tenfold freshly diluted Folin-Ciocalteu reagent in 96 well plates. Then, $0.125 \mathrm{~mL}$ of $7.5 \%$ sodium carbonate was added to each well. The plates were incubated in the dark for $60 \mathrm{~min}$ at room temperature. The absorbance values were measured at $765 \mathrm{~nm}$ using the UV microplate reader. The results were expressed as milligrams of gallic acid equivalent per gram of smoke powder or liquid smoke (mg GAE/g).

Total flavonoid content (TFC) was determined using quercetin as the standard by an aluminium chloride method (Essien et al., 2020). The solutions $(0.025 \mathrm{~mL})$ and quercetin standards were mixed with $0.1 \mathrm{~mL}$ of distilled water and $0.01 \mathrm{~mL}$ of $5 \%$ sodium nitrite in 96 well plates. Then, $0.015 \mathrm{~mL}$ of $10 \% \mathrm{AlCl}_{3}$ and $0.050 \mathrm{~mL}$ of $1 \mathrm{~mol} / \mathrm{L} \mathrm{NaOH}$ were added to the well plates. After adding $0.05 \mathrm{~mL}$ of distilled water, the plates were incubated in the dark for $60 \mathrm{~min}$ at room temperature. The absorbance values were measured against a reagent blank at $510 \mathrm{~nm}$. The results were expressed as milligrams of quercetin equivalent per gram of smoke powder or liquid smoke (mg QE/g).

Ferric reducing antioxidant power assay (FRAP) was conducted following a previous report (Kheirkhah et al., 2019). FRAP reagent was prepared by mixing the 2,3,5-triphenyltetrazolium chloride (TPTZ) solution $(10 \mathrm{mmol} / \mathrm{L} \mathrm{TPTZ}$ in $40 \mathrm{mmol} / \mathrm{L} \mathrm{HCl}), 20 \mathrm{mmol} / \mathrm{L} \mathrm{FeCl}_{3}$ and $300 \mathrm{mmol} / \mathrm{L}$ sodium acetate buffer $(\mathrm{pH} 3.6)$ at a ratio of 1:1:10. Smoke samples $(0.001 \mathrm{~mL})$ and Trolox standards were mixed with $0.2 \mathrm{~mL}$ of FRAP reagent in 96 well plates. The absorbance values were measured at $593 \mathrm{~nm}$ against a reagent blank after incubation for $60 \mathrm{~min}$ at room temperature. The results were expressed as milligrams of Trolox equivalent per gram of smoke powder or liquid smoke (mg TE/g).

A previous study was followed to determine DPPH scavenging capacity (Essien et al., 2020). The DPPH (1,1-diphenyl-2-picrylhydrazyl) reagent was firstly dissolved in ethanol at a concentration of $40 \mathrm{mg} / \mathrm{L}$. Then, $0.2 \mathrm{~mL}$ of DPPH solution was mixed with $0.01 \mathrm{~mL}$ of each sample, Trolox standards and blank in 96 well plates. The absorbance values were measured at $517 \mathrm{~nm}$ after incubation for $60 \mathrm{~min}$ at room temperature. The DPPH scavenging capacity was expressed as milligrams of Trolox equivalent per gram of smoke powder or liquid smoke (mg TE/g).

The retention efficiency of each bioactive value is calculated according to Eq. (2):

$\mathrm{RE}=\frac{V_{\text {Powder }} \times \mathrm{Y}_{\text {Product }}}{V_{\mathrm{LS}} / \mathrm{P}_{\mathrm{TSS}}} \times 100$

where $R E$ is retention efficiency (\%), $V_{\text {Powder }}$ is the bioactive value (TPC, TFC, FRAP or DPPH) of powder products, $\mathrm{Y}_{\text {Product }}$ is the yield of powder products, $V_{\mathrm{LS}}$ is the bioactive value of pure liquid smoke and $\mathrm{P}_{\mathrm{TSS}}$ is the mass percentage of total soluble solid in the feed solution.

\section{GC-MS and Principal Component Analysis}

Gas chromatography-mass spectrometry (GC-MS) analysis was conducted to identify the volatile compounds. The smoke powder products and pure liquid smoke were dissolved and diluted in distilled water to a concentration of $250 \mathrm{mg} / \mathrm{mL}$. Then the solutions were mixed with dichloromethane at a volume ratio of $1 / 2$ (solution/dichloromethane), and the mixtures were agitated at $200 \mathrm{rpm}$ for $6 \mathrm{~h}$. The dichloromethane extracts were then filtered by $0.2 \mu \mathrm{m}$ syringe filters. Each dichloromethane extract was prepared in triplicate for GC-MS analysis. This preparation method followed a previous study with minor modifications (María D. Guillén \& Ibargoitia, 1998).

The GC-MS instrument (Shimadzu QP-5000) was equipped with a DB-5HT column $(30 \mathrm{~m} \times 0.25 \mathrm{~mm} \times 0.1 \mu \mathrm{m})$. Dichloromethane extract $(1 \mu \mathrm{L})$ was injected at an injection temperature of $280^{\circ} \mathrm{C}$. The oven temperature was increased from 50 to $250^{\circ} \mathrm{C}$ by $20^{\circ} \mathrm{C} / \mathrm{min}$ and then was held for $5 \mathrm{~min}$. Mass spectra were operated in electron ionisation mode at $70 \mathrm{eV}$, and the mass range was 50-300 amu for acquisition. Volatile compounds were identified by comparing the mass spectra with those in the library NIST and by comparing the data results with previous studies (Petzold et al., 2014; Taruna Syah et al., 2016; Xin et al., 2021). Their relative abundances were expressed as the peak area percentages of the total ionisation chromatogram (TIC).

Principal component analysis (PCA) as a useful chemometric tool can reduce the experimental data dimension for ease of interpretation. It can transform a large set of interrelated variables into principal components. This study used principal component analysis (PCA) to understand the difference between liquid smoke and produced powders in terms of their chemical composition. The smoke flavouring samples were set as the observations, and peak area percentages of identified compounds by GC-MS were set as the variations. A MATLAB toolbox was used with MATLAB R2020a software to 
conduct PCA (Ballabio, 2015). The toolbox gives visualising results, including plots of scores and loadings and numerical values of eigenvalues.

\section{Determination of Physical Properties}

The morphology of the smoke powders was determined using a scanning electron microscope (Hitachi SU-70 Schottky field SEM). Smoke powder samples were sprinkled on the double-sided conductive carbon tabs and glued onto the SEM mounts. The samples were coated with platinum for $100 \mathrm{~s}$ at room temperature.

Particle sizes of the smoke powders and pure maltodextrin were measured by a particle size analyser (Malvern Mastersizer 2000, Malvern Instruments Ltd) with a dry dispersion module (Scirocco 2000). The weighted-average volume diameter was expressed as diameter $D_{[4,3]}$, assuming spherical particles with the same volume as the actual particles. Particle size distribution (PSD) is calculated according to Eq. (3):

$\operatorname{PSD}=\frac{\mathrm{d}(0.9)-\mathrm{d}(0.1)}{\mathrm{d}(0.5)}$

where $\mathrm{d}(0.9), \mathrm{d}(0.5)$ and $\mathrm{d}(0.1)$ are respectively particle diameters at 90,50 , and $10 \%$ of the cumulative size distribution curve from Mastersizer analysis results (Tupuna et al., 2018).

Bulk density and tapped density were determined by following a reported method (Caliskan \& Dirim, 2016). Briefly, $20 \mathrm{~g}$ of each powder sample or maltodextrin was gently loaded into a $100 \mathrm{~mL}$ graduated cylinder. The sample weight was divided by the measured volume to obtain bulk density $\left(\rho_{\text {bulk }}, \mathrm{g} / \mathrm{mL}\right)$. The tapped density ( $\rho_{\text {tapped }}, \mathrm{g} /$ $\mathrm{mL}$ ) was obtained after tapping the cylinder 120 times and then measuring the sample volume.

Carr index (CI) and Hausner ratio (HR) were evaluated for the flowability and cohesiveness of the six powder samples and maltodextrin (Caliskan \& Dirim, 2016). The $\mathrm{CI}$ and HR values are calculated according to Eqs. (4) and (5):

$\mathrm{CI}=\frac{\rho_{\text {tapped }}-\rho_{\text {bulk }}}{\rho_{\text {tapped }}} \times 100$

$\mathrm{HR}=\frac{\rho_{\text {tapped }}}{\rho_{\text {bulk }}}$

Water content of the powder samples and maltodextrin was measured by weight difference before and after placing the sample in a drying oven at $105{ }^{\circ} \mathrm{C}$ until no more weight loss.

\section{Statistical Analysis}

All of the drying processes and analyses in this study were conducted in triplicate, and the results were presented as mean values \pm standard deviation $(n=3)$. Analysis of variance (ANOVA) was performed, and the difference between means was analysed using Duncan's test. Statistical significance was considered at $p<0.05$. All statistical analysis was performed using SPSS 9.05 (Chicago, USA).

\section{Results and Discussion}

\section{Product Yield}

At the mass ratios of 6:1, 5:1 and 4:1 (liquid smoke/maltodextrin, w/w), three solutions were spray-dried and freezedried separately. In spray-drying, the product in the drying chamber, cyclone and cyclone container was weighed and collected. The solid formed in freeze-drying chamber was weighed and collected as freeze-drying product. Product yields in these two drying processes are shown in Fig. 1. Freeze-drying with the highest maltodextrin ratio (FZD-4/1) showed the highest yield of $96.9 \pm 0.8 \mathrm{wt} \%$. Spray-drying with the lowest maltodextrin ratio (SPD-6/1) showed the lowest yield of $73.3 \pm 0.5 \mathrm{wt} \%$. The comparison of the two drying methods with the same solutions showed that freeze-drying could lead to a higher yield. This trend was also reported in the studies of spray and freeze-drying of strawberry flavour (Pellicer et al., 2019), black glutinous rice (Laokuldilok \& Kanha, 2015) and orange powder (Barbosa et al., 2015). The loss of volatile compounds occurred in spray-drying due to a

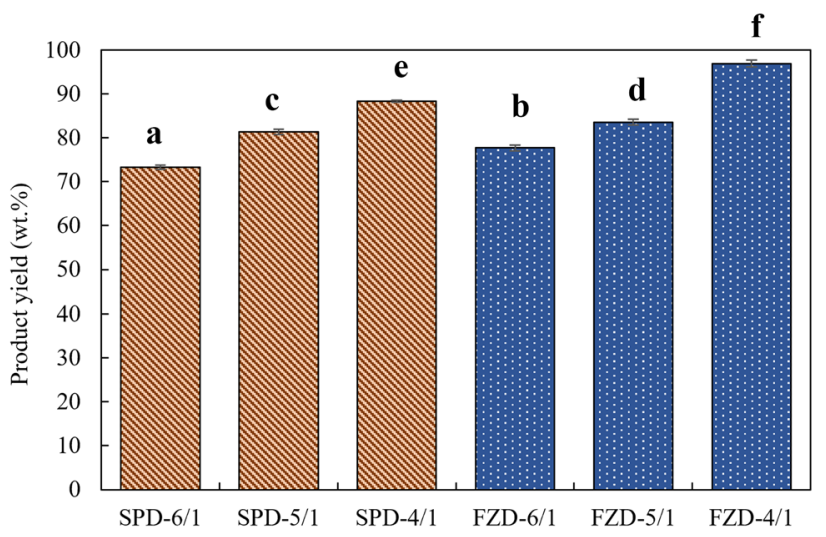

Fig. 1 Product yields in spray and freeze-drying of liquid smoke and maltodextrin solutions. Error bars correspond to standard deviations of the mean $(n=3)$; the columns with different letters indicate significant difference at $p<0.05$ 
Table 1 TPC, TFC, FRAP and DPPH values of liquid smoke and smoke powders

\begin{tabular}{|c|c|c|c|c|c|c|c|}
\hline & SPD-6/1 & SPD-5/1 & SPD-4/1 & FZD-6/1 & FZD-5/1 & FZD-4/1 & Liquid smoke \\
\hline TPC, mg GAE/g & $82.9^{\mathrm{e}}$ & $76.1^{\mathrm{d}}$ & $73.1^{\mathrm{c}}$ & $86.4^{\mathrm{f}}$ & $75.7^{\mathrm{d}}$ & $65.4^{\mathrm{b}}$ & $40.1^{\mathrm{a}}$ \\
\hline \pm std & 0.4 & 0.7 & 1.3 & 0.9 & 1.0 & 0.2 & 0.6 \\
\hline TFC, mg QE/g & $100.6^{\mathrm{f}}$ & $95.2^{\mathrm{d}}$ & $86.3^{\mathrm{c}}$ & $101.2^{\mathrm{f}}$ & $88.0^{\mathrm{c}}$ & $77.0^{\mathrm{b}}$ & $38.5^{\mathrm{a}}$ \\
\hline \pm std & 4.3 & 2.5 & 1.4 & 1.9 & 2.5 & 0.7 & 0.5 \\
\hline FRAP, mg TE/g & $91.7^{\mathrm{d}}$ & $86.4^{\mathrm{b}, \mathrm{c}}$ & $82.7^{\mathrm{b}}$ & $89.7^{\mathrm{c}, \mathrm{d}}$ & $85.4^{\mathrm{b}, \mathrm{c}}$ & $81.5^{\mathrm{b}}$ & $46.9^{\mathrm{a}}$ \\
\hline \pm std & 1.2 & 1.5 & 2.9 & 1.9 & 2.3 & 2.1 & 2.8 \\
\hline DPPH, mg TE/g & $39.2^{\mathrm{d}, \mathrm{e}}$ & $45.3^{\mathrm{e}}$ & $41.3^{\mathrm{d}, \mathrm{e}}$ & $36.8^{\mathrm{c}, \mathrm{d}}$ & $32.5^{\mathrm{c}}$ & $23.5^{\mathrm{b}}$ & $13.6^{\mathrm{a}}$ \\
\hline \pm std & 4.7 & 2.3 & 1.0 & 2.4 & 2.0 & 3.6 & 0.7 \\
\hline
\end{tabular}

Results in this table are expressed as mean \pm standard deviation. Mean values with the same superscript letters within a row are not significantly different at $p<0.05$ high temperature. Meanwhile, the fine particles not captured by the spray drier cyclone also contributed to the mass loss.

Figure 1 also indicates that increasing the maltodextrin concentration led to a higher product yield in both drying processes. Maltodextrin is a common encapsulant agent for bioactive compounds. Previous studies also showed that a higher concentration of encapsulant agents improved encapsulation efficiency (Caliskan \& Dirim, 2016; Rezende et al., 2018; Taruna Syah et al., 2016). However, it was suggested that the concentration of encapsulant agent should be no more than 30\% in spray-drying (Ghosh, 2006), since high maltodextrin concentration also led to a dilution of bioactive compounds in the encapsulates.

\section{Bioactive Activities}

Table 1 shows the bioactive activities of pure liquid smoke and smoke powders in terms of TPC, TFC, FRAP and DPPH. Figure 2 illustrates the retention efficiency of bioactive activities via each encapsulation method. Equation (2) is used to calculate the efficiency, which eliminated the dilution effects due to the increase of the maltodextrin concentration in different solutions.
Total phenolic content (TPC) value is an important indicator of bioactive activities for liquid smoke. The phenolic compounds (produced from pyrolysis of lignin) contribute to the effects of smoke flavouring, aroma profile, antimicrobial and antioxidant capacity (Lingbeck et al., 2014). As shown in Table 1, the TPC value increased from $40.1 \mathrm{mg}$ $\mathrm{GAE} / \mathrm{g}$ for pure liquid smoke to the range of $65.4-86.4 \mathrm{mg}$ GAE/g for smoke powders. Spray-drying and freeze-drying processes retained the phenolics to the same extent in this study. Table 1 also shows the TPC value decreased with the increase of maltodextrin concentration due to the dilution effect. Figure 2 proves that using a higher concentration of encapsulant agent increases the retention efficiency from 40 to $50 \%$. The same effect of encapsulant agent on retention efficiency was observed in previous studies (Caliskan \& Dirim, 2016; Taruna Syah et al., 2016).

Flavonoids are the largest group of naturally occurring phenolic compounds (Sulaiman \& Balachandran, 2012). Total flavonoid content (TFC) of liquid smoke has rarely been reported. The results of this study indicated that TFC of a fast pyrolysis liquid smoke was approximately $38.5 \mathrm{mg}$ $\mathrm{QE} / \mathrm{g}$. It was increased by more than twofold after spraydrying or freeze-drying, and both drying processes showed
Fig. 2 Retention efficiency (\%) of bioactive activities in different encapsulation processes. Error bars correspond to standard deviations of the mean $(n=3)$; the columns with different letters within each cluster indicate significant difference at $p<0.05$

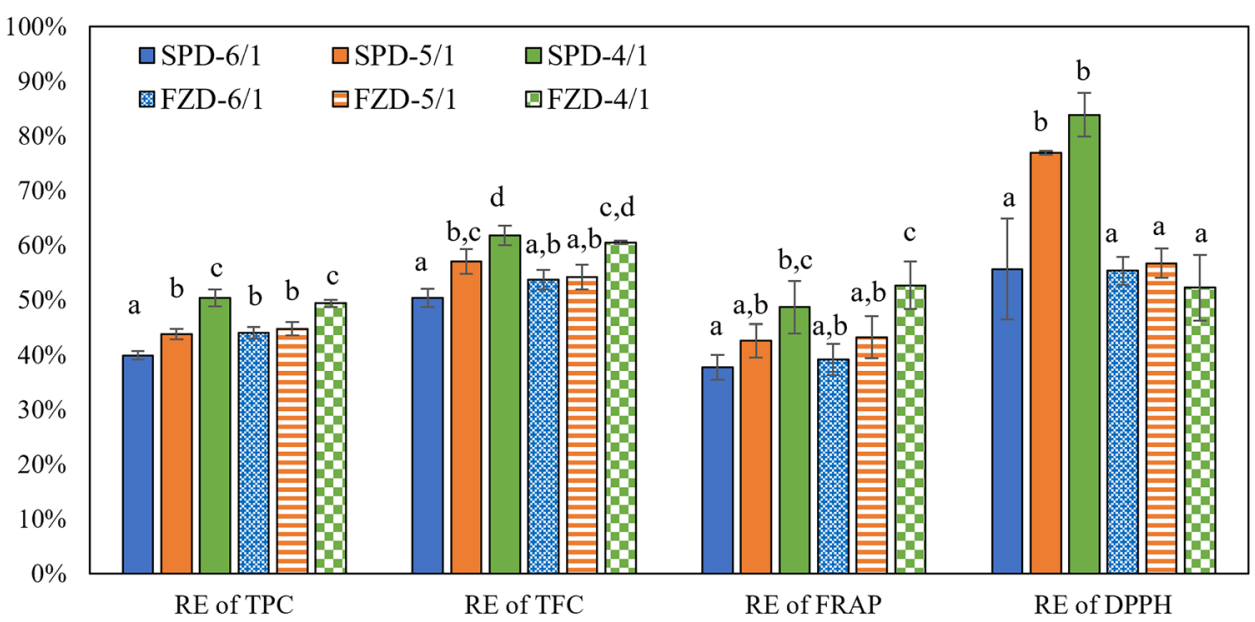


similar effects on the retention of flavonoids and retention efficiency.

Antioxidant capacity (FRAP and DPPH) of the kanuka liquid smoke produced by fast pyrolysis were much higher than those reported previously (Loo et al., 2007; Ma et al., 2013). For instance, DPPH value of commercial liquid smoke was reported in the range of 0.1 to $4.8 \mathrm{mg} \mathrm{TE} / \mathrm{g}$ (Soldera et al., 2008). Fast pyrolysis could effectively decompose lignin polymers leading to a high proportion of phenolics in the resultant liquid smoke (Xin et al., 2021). Spray-drying or freeze-drying of the liquid smoke led to the further increase in antioxidant capacity (approximately twofold) as shown in Table 1.

\section{Chemical Composition}

The volatile compounds of pure kanuka liquid smoke and smoke powders were identified by GC-MS analysis. Peak area percentages of identified compounds are presented in the Supplementary data (Table S1). The compounds were classified by their main functional groups as acids, carbonyls, esters, furans and phenols. The results showed the most abundant
Fig. 3 Scores (a) and loadings (b) plots of PC1 and PC2 for liquid smoke, spray dried powders and freeze dried powders (a)

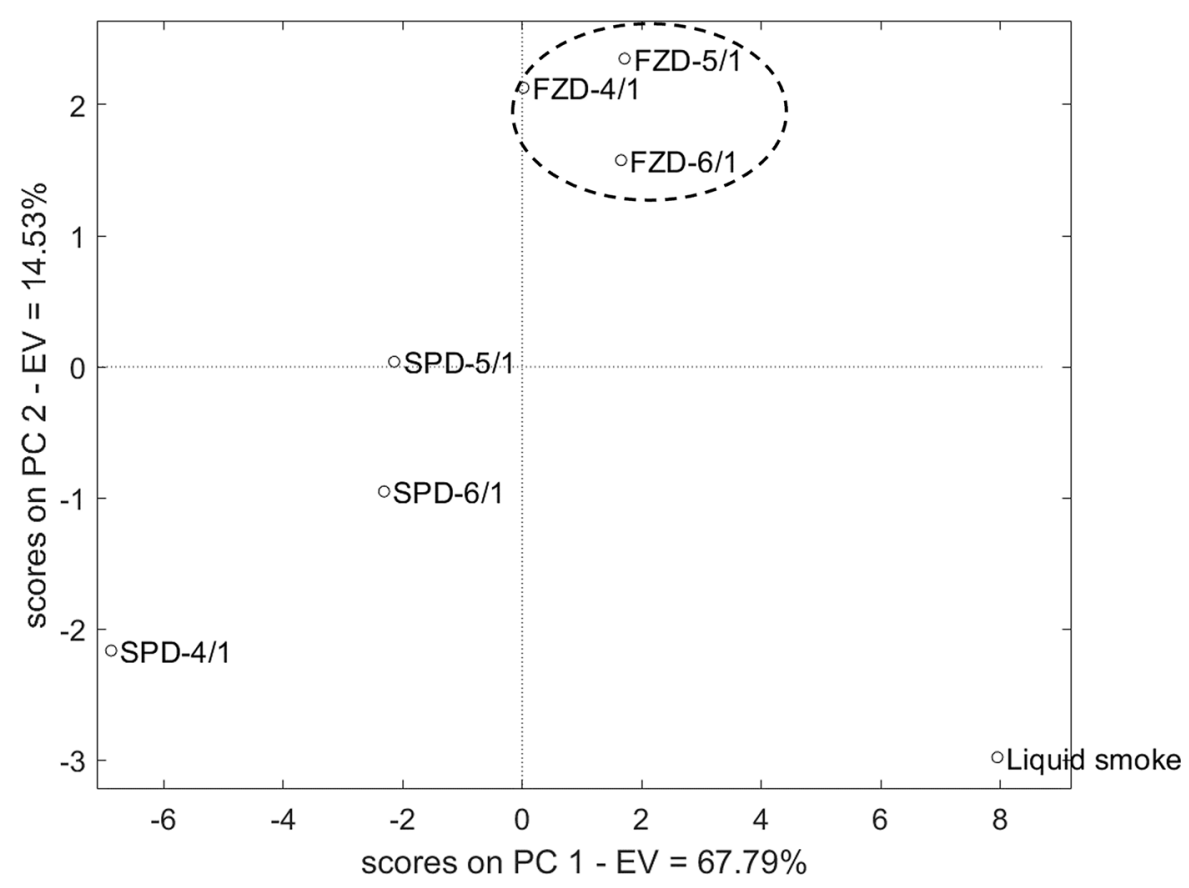

(b)

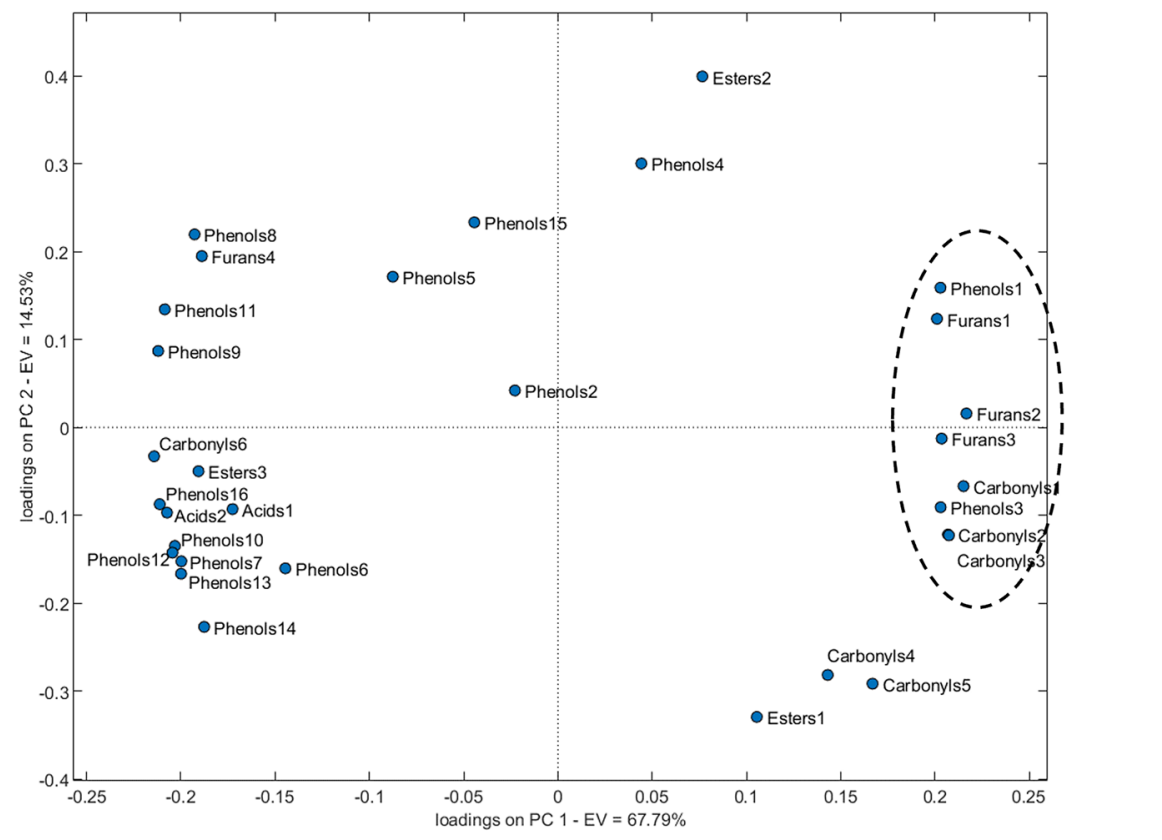


compounds in liquid smoke and smoke powders were the same, which were guaiacol, 2-hydroxy-2-cyclopenten-1-one, $2(5 \mathrm{H})$-furanone and syringol in sequence. Guaiacol, a common compound in liquid smoke, has been reported frequently in previous reports (Guillén et al., 1995; Surboyo et al., 2019). Guaiacol and its derivatives are the main smoky flavour and aroma in liquid smoke (Schranz et al., 2017). Syringol, as one of the guaiacol's derivatives, presents the most favoured aroma (Montazeri et al., 2012). 2-Hydroxy-2-cyclopenten1 -one from carbonyls group and $2(5 \mathrm{H})$-furanone from furans groups can soften the heavy smoky aroma associated with phenols and improve the overall sensory properties of the treated food (Maga, 1987).

Principal component analysis (PCA) scores and loadings plots are shown in Fig. 3 with the first two principal components, $\mathrm{PC} 1$ and $\mathrm{PC} 2$. PC1 described the largest possible variation $(67.79 \%)$, and $\mathrm{PC} 2$ the second-highest variation $(14.53 \%)$. Since the value of PC1 is high, the variations among the seven smoke flavouring samples can be explained by the locations on the horizontal direction in the loadings plot (Fig. 3b). It shows carbonyls 1, 2, 3 (Butanal, 3-Methyl2-cyclopenten-1-one, 2-Hydroxy-2-cyclopenten-1-one), furans 1, 2 (2(5H)-Furanone, 3-Methyl-2(5H)-furanone), and phenols 1, 3 (Phenol, Guaiacol) are located farthest to the right. Presumably, partial loss of these compounds during freeze or spray-drying processes led the changes of chemical compositions of smoke powders.

The pure liquid smoke is located far away from the powder samples, as shown in Fig. 3a indicates its chemical composition is relatively different from smoke powders. Three freeze-dried powders are clustered, indicating that the chemical composition is relatively similar. In contrast, three spray-dried powders are scattered in the scores plot. It can be concluded that maltodextrin concentration is a more important parameter in spray-drying than freeze-drying. A lower concentration led to more losses of volatile compounds.

\section{Physical Properties}

SEM images of smoke powder particles are shown in Fig. 4 . The particles produced by spray-drying had a spherical shape with sizes at the scale of $10 \mu \mathrm{m}$. The particles produced by freeze-drying had irregular shapes, and their particle sizes were relatively large at the scale of $100 \mu \mathrm{m}$. Because freeze-drying of liquid smoke solutions resulted in an amorphous glassy mass, it was ground using a mortar and pestle.

Table 2 shows the physical properties of the smoke powders and the carrier maltodextrin as a reference. The particle size $\left(D_{[4,3]}\right)$ of spray-dried powders was in the range of 6.3 to $6.9 \mu \mathrm{m}$ with no significant difference by using the labscale spray dryer. It is noted that the particle size is strongly affected by the spray-drying inlet temperature, feeding rate, feed composition or carrier type (Cortés-Rojas et al., 2015). In a previous study, a smoke powder produced by spraydrying had an average particle size of $0.013 \mu \mathrm{m}$ (Saloko et al., 2014). That nano-encapsulate was prepared from a mixture of liquid smoke, chitosan, and maltodextrin. While in another study, the particle size of spray-dried powder was in the range of 0.5 to $12.7 \mu \mathrm{m}$ (Taruna Syah et al., 2016). A smaller particle size would make spray-dried smoke powder perform better on food preservation by easily penetrating the treated food. The PSD value for spray-dried powders was decreased from 2.57 to 2.16 by increasing the maltodextrin concentration. The increase of maltodextrin concentration led to less homogeneous particle sizes in spray-drying, and this trend was also reported in another study of norbixin spray-drying (Tupuna et al., 2018).

Due to the different powder preparing methods, particle sizes of freeze-dried powders were much larger than the spray-dried powders. The particle size was decreased by increasing the carrier concentration, and $D_{[4,3]}$ value of FZD-4/1 $(134.7 \mu \mathrm{m})$ was close to the maltodextrin powder
Fig. 4 SEM images of particles from spray and freeze-drying of liquid smoke

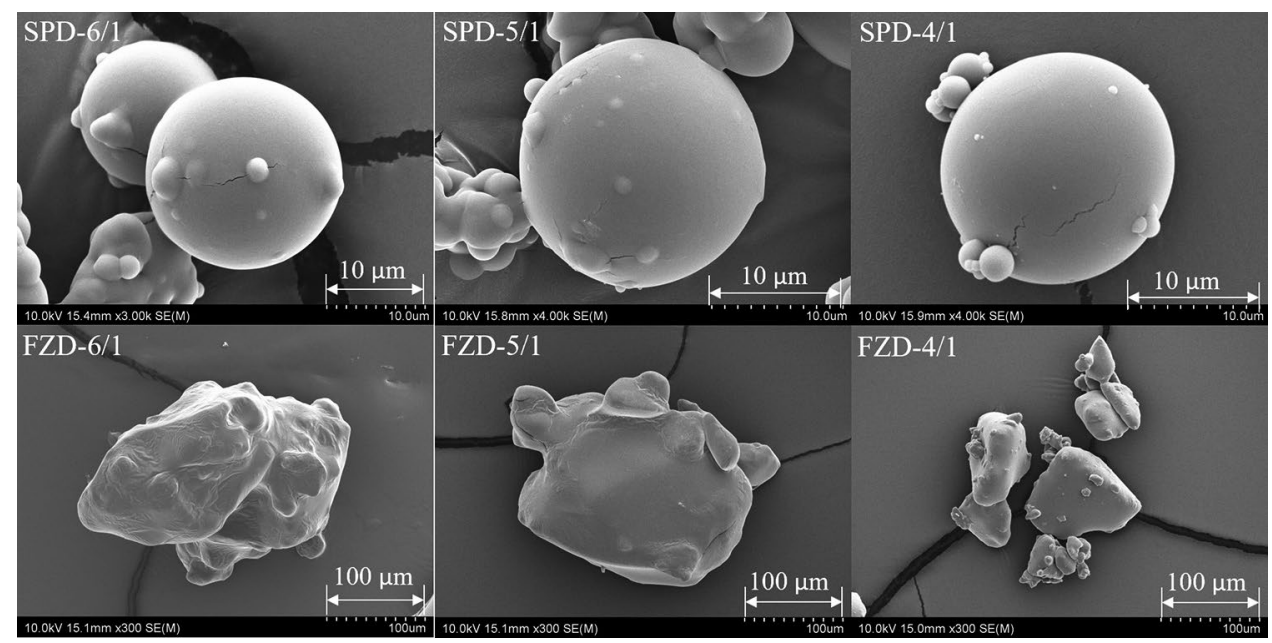


Table 2 Physicochemical properties of smoke powders and maltodextrin

\begin{tabular}{llllllll}
\hline & SPD-6/1 & SPD-5/1 & SPD-4/1 & FZD-6/1 & FZD-5/1 & FZD-4/1 & Maltodextrin \\
\hline $\mathrm{D}_{[4,3]}, \mu \mathrm{m}$ & $6.9^{\mathrm{a}}$ & $6.3^{\mathrm{a}}$ & $6.4^{\mathrm{a}}$ & $580.4^{\mathrm{d}}$ & $500.1^{\mathrm{d}}$ & $134.7^{\mathrm{c}}$ & $96.1^{\mathrm{b}}$ \\
\pm std & 0.2 & 0.1 & 0.3 & 29.0 & $7.7^{\mathrm{a}}$ & 2.1 & 0.9 \\
PSD & $2.57^{\mathrm{g}}$ & $2.24^{\mathrm{f}}$ & $2.16^{\mathrm{e}}$ & $1.39^{\mathrm{b}}$ & $1.33^{\mathrm{a}}$ & $1.63^{\mathrm{c}}$ & $1.99^{\mathrm{d}}$ \\
\pm std & 0.06 & 0.01 & 0.02 & 0.02 & 0.02 & 0.00 & 0.01 \\
Bulk density, g/mL & $0.224^{\mathrm{a}}$ & $0.290^{\mathrm{b}}$ & $0.349^{\mathrm{c}}$ & $0.397^{\mathrm{d}}$ & $0.482^{\mathrm{f}}$ & $0.513^{\mathrm{g}}$ & $0.460^{\mathrm{e}}$ \\
\pm std & 0.003 & 0.003 & 0.007 & 0.007 & 0.003 & 0.003 & 0.002 \\
Tapped density, g/ml & $0.275^{\mathrm{a}}$ & $0.367^{\mathrm{b}}$ & $0.422^{\mathrm{c}}$ & $0.451^{\mathrm{d}}$ & $0.552^{\mathrm{e}}$ & $0.589^{\mathrm{f}}$ & $0.550^{\mathrm{e}}$ \\
\pm std & 0.002 & 0.005 & 0.009 & 0.004 & 0.005 & 0.004 & 0.005 \\
CI, $\%$ & $18.6^{\mathrm{c}}$ & $20.9^{\mathrm{d}}$ & $17.2^{\mathrm{b}, \mathrm{c}}$ & $12.1^{\mathrm{a}}$ & $12.7^{\mathrm{a}}$ & $13.0^{\mathrm{a}}$ & $16.3^{\mathrm{b}}$ \\
\pm std & 0.7 & 0.5 & 1.2 & 0.9 & 1.0 & 0.0 & 0.6 \\
HR, $\%$ & $1.23^{\mathrm{b}}$ & $1.26^{\mathrm{c}, \mathrm{d}}$ & $1.21^{\mathrm{b}}$ & $1.14^{\mathrm{d}, \mathrm{e}}$ & $1.15^{\mathrm{c}}$ & $1.15^{\mathrm{e}}$ & $1.20^{\mathrm{a}}$ \\
\pm std & 0.01 & 0.01 & 0.02 & 0.01 & 0.01 & 0.00 & 0.01 \\
Moisture content, wt.\% & $8.5^{\mathrm{b}}$ & $10.1^{\mathrm{c}, \mathrm{d}}$ & $7.8^{\mathrm{b}}$ & $10.9^{\mathrm{d}, \mathrm{e}}$ & $9.7^{\mathrm{c}}$ & $12.0^{\mathrm{e}}$ & $4.7^{\mathrm{a}}$ \\
\pm std & 0.9 & 0.6 & 0.7 & 0.3 & 0.3 & 0.2 & 0.2 \\
\hline Resuld & & & & & & &
\end{tabular}

Results in this table are expressed as mean \pm standard deviation. Mean values with the same superscript letters within a row are not significantly different at $p<0.05$
(96.1 $\mu \mathrm{m})$. A similar observation was reported by Rezende et al. (2018), and the relatively large size of freeze-dried particles could be due to its low grindability index.

As presented in Table 2, bulk and tapped density values of spray-dried powders were lower than the values of maltodextrin. In contrast, the bulk and tapped densities of freeze-dried powder were in the range of $0.397-0.513 \mathrm{~g} / \mathrm{mL}$, close to the density values of maltodextrin. With the increase of maltodextrin concentration, bulk density was increased for both dried powders. The same trend can be observed in the relation of tapped density and the carrier concentration. Similar results were reported in studies of freeze and spraydrying of sumac extract (Caliskan \& Dirim, 2016), spraydrying of Ber juice (Singh et al., 2014) and spray-drying of tea extract (Nadeem et al., 2011).

Carr index (CI) and Hausner ratio (HR) were used to evaluating the flowability and cohesiveness of the smoke powders (Table 2). The powder flowability is classified by value as very good $(\mathrm{CI}<15)$, good $(\mathrm{CI}=15-20)$, fair $(\mathrm{CI}=20-35)$, bad $(\mathrm{CI}=35-45)$ and very bad $(\mathrm{CI}>45)$ (Jinapong et al., 2008). As presented in Table 2, spray-dried powders can be classified as good or fair, and freeze-dried powders as very good. The powder cohesiveness based is classified as low $(\mathrm{HR}<1.2)$, intermediate $(\mathrm{HR}=1.2-1.4)$ and high $(\mathrm{HR}>1.4)$ (Jinapong et al., 2008). The cohesiveness of spray-dried powders was found as intermediate and freeze-dried powders as low. A lower HR value means that the powder is less cohesive and freer to flow. In this study, freeze-dried powders showed better flowability and cohesiveness than the spray-dried ones.

The water content of all the smoke powders was higher than that of maltodextrin, as shown in Table 2. Since the values were measured by oven-heating at a temperature of $105{ }^{\circ} \mathrm{C}$, the loss of volatile chemicals could contribute to the measurement.

\section{Conclusion}

Spray-drying and freeze-drying showed good performance in encapsulating flavour and bioactive compounds of liquid smoke. Both drying processes were able to concentrate the phenolic and flavonoid compounds by approximately two times or more. Freeze-drying had a slightly higher retention efficiency than spray-drying with the same feed solution. A higher concentration of carrier agent also increased retention efficiency in both drying processes. Spray-drying did not damage bioactive compounds at high temperature conditions, while both drying processes led to a partial loss of small molecular carbonyls, furans and phenols. Compared with freeze-dried powder, spray-dried powder had a tenfold smaller particle size, which would be advantageous for food preservation. On the other hand, freeze-dried powder had more handling convenience because of higher flowability and lower cohesiveness.

Supplementary Information The online version contains supplementary material available at https://doi.org/10.1007/s11947-022-02779-3.

Acknowledgements The authors acknowledge the University of Auckland FRDF Grant 3719621. We would like to thank the technical assistance of Adrian Guanyu An. 
Funding Open Access funding enabled and organized by CAUL and its Member Institutions.

Data Availability All data generated or analysed during this study are included in this published article and its supplementary information file.

\section{Declarations}

Competing Interests The authors declare no competing interests.

Open Access This article is licensed under a Creative Commons Attribution 4.0 International License, which permits use, sharing, adaptation, distribution and reproduction in any medium or format, as long as you give appropriate credit to the original author(s) and the source, provide a link to the Creative Commons licence, and indicate if changes were made. The images or other third party material in this article are included in the article's Creative Commons licence, unless indicated otherwise in a credit line to the material. If material is not included in the article's Creative Commons licence and your intended use is not permitted by statutory regulation or exceeds the permitted use, you will need to obtain permission directly from the copyright holder. To view a copy of this licence, visit http://creativecommons.org/licenses/by/4.0/.

\section{References}

Ariestya, D. I., Swastawati, F., \& Susanto, E. (2016). Antimicrobial activity of microencapsulation liquid smoke on tilapia [Oreochromis Niloticus (Linnaeus, 1758)] meat for preservatives in cold storage $\left( \pm 5 \mathrm{C}^{\circ}\right)$. Aquatic Procedia, 7, 19-27. https://doi.org/10. 1016/j.aqpro.2016.07.003

Arvanitoyannis, I. S., \& Kotsanopoulos, K. V. (2012). Smoking of fish and seafood: History, methods and effects on physical, nutritional and microbiological properties. Food and Bioprocess Technology, 5(3), 831-853.

Ballabio, D. (2015). A MATLAB toolbox for principal component analysis and unsupervised exploration of data structure. Chemometrics and Intelligent Laboratory Systems, 149, 1-9. https://doi. org/10.1016/j.chemolab.2015.10.003

Barbosa, J., Borges, S., Amorim, M., Pereira, M. J., Oliveira, A., Pintado, M. E., \& Teixeira, P. (2015). Comparison of spray drying, freeze drying and convective hot air drying for the production of a probiotic orange powder. Journal of Functional Foods, 17, 340-351. https://doi.org/10.1016/j.jff.2015.06.001

Belščak-Cvitanović, A., Lević, S., Kalušević, A., Špoljarić, I., Đorđević, V., Komes, D., et al. (2015). Efficiency assessment of natural biopolymers as encapsulants of green tea (Camellia sinensis L.) bioactive compounds by spray drying. Food and bioprocess technology, 8(12), 2444-2460.

Caliskan, G., \& Dirim, S. N. (2016). The effect of different drying processes and the amounts of maltodextrin addition on the powder properties of sumac extract powders. Powder Technology, 287, 308-314. https://doi.org/10.1016/j.powtec.2015.10.019

Celli, G. B., Ghanem, A., \& Brooks, M.S.-L. (2015). Bioactive encapsulated powders for functional foods-a review of methods and current limitations. Food and Bioprocess Technology, 8(9), $1825-1837$.

Condurache, N. N., Aprodu, I., Crăciunescu, O., Tatia, R., Horincar, G., Barbu, V., et al. (2019). Probing the functionality of bioactives from eggplant peel extracts through extraction and microencapsulation in different polymers and whey protein hydrolysates. Food and Bioprocess Technology, 12(8), 1316-1329.
Cortés-Rojas, D. F., Souza, C. R. F., \& Oliveira, W. P. (2015). Optimization of spray drying conditions for production of Bidens pilosa L. dried extract. Chemical Engineering Research and Design, 93, 366-376.

Desai, K. G. H., \& Jin Park, H. (2005). Recent developments in microencapsulation of food ingredients. Drying Technology, 23(7), 1361-1394.

Dimakopoulou-Papazoglou, D., \& Katsanidis, E. (2017). Effect of maltodextrin, sodium chloride, and liquid smoke on the mass transfer kinetics and storage stability of osmotically dehydrated beef meat. Food and Bioprocess Technology, 10(11), 2034-2045.

Essien, S. O., Baroutian, S., Dell, K., \& Young, B. (2019). Value-added potential of new Zealand mānuka and kānuka products: A review. Industrial Crops and Products, 130, 198-207. https://doi.org/10. 1016/j.indcrop.2018.12.083

Essien, S., Young, B., \& Baroutian, S. (2020). Subcritical water extraction for selective recovery of phenolic bioactives from kānuka leaves. The Journal of Supercritical Fluids, 158, 104721.

Ghosh, S. K. (2006). Functional coatings and microencapsulation: a general perspective. Functional coatings, 1-28.

Guillén, M. D., \& Ibargoitia, M. L. (1998). New components with potential antioxidant and organoleptic properties, detected for the first time in liquid smoke flavoring preparations. Journal of Agricultural and Food Chemistry, 46(4), 1276-1285. https://doi. org/10.1021/jf970952x

Guillén, M. D., Manzanos, M. J., \& Zabala, L. (1995). Study of a commercial liquid smoke flavoring by means of gas chromatography/ mass spectrometry and fourier transform infrared spectroscopy. Journal of Agricultural and Food Chemistry, 43(2), 463-468. https://doi.org/10.1021/jf00050a039

Jinapong, N., Suphantharika, M., \& Jamnong, P. (2008). Production of instant soymilk powders by ultrafiltration, spray drying and fluidized bed agglomeration. Journal of Food Engineering, 84(2), 194-205. https://doi.org/10.1016/j.jfoodeng.2007.04.032

Kheirkhah, H., Baroutian, S., \& Quek, S. Y. (2019). Evaluation of bioactive compounds extracted from Hayward kiwifruit pomace by subcritical water extraction. Food and Bioproducts Processing, $115,143-153$.

Laokuldilok, T., \& Kanha, N. (2015). Effects of processing conditions on powder properties of black glutinous rice (Oryza sativa L.) bran anthocyanins produced by spray drying and freeze drying. LWT - Food Science and Technology, 64(1), 405-411. https://doi. org/10.1016/j.lwt.2015.05.015

Lingbeck, J. M., Cordero, P., O’Bryan, C. A., Johnson, M. G., Ricke, S. C., \& Crandall, P. G. (2014). Functionality of liquid smoke as an all-natural antimicrobial in food preservation. Meat Science, 97(2), 197-206. https://doi.org/10.1016/j.meatsci.2014.02.003

Loo, A. Y., Jain, K., \& Darah, I. (2007). Antioxidant and radical scavenging activities of the pyroligneous acid from a mangrove plant, Rhizophora apiculata. Food Chemistry, 104(1), 300-307. https:// doi.org/10.1016/j.foodchem.2006.11.048

Ma, C., Song, K., Yu, J., Yang, L., Zhao, C., Wang, W., et al. (2013). Pyrolysis process and antioxidant activity of pyroligneous acid from Rosmarinus officinalis leaves. Journal of Analytical and Applied Pyrolysis, 104, 38-47.

Maga, J. A. (1987). The flavor chemistry of wood smoke. Food Reviews International, 9129(1987), 139-183. https://doi.org/10.1080/ 87559128709540810

Maga, J. A. (2018). Smoke in food processing (1st ed.). CRC Press. https://doi.org/10.1201/9781351076647

Maia, P. D. D. S., dos Santos Baião, D., da Silva, V. P. F., de Araujo Calado, V. M., Queiroz, C., Pedrosa, C., et al. (2019). Highly stable microparticles of cashew apple (Anacardium occidentale L.) juice with maltodextrin and chemically modified starch. Food and Bioprocess Technology, 12(12), 2107-2119. 
Montazeri, N., Crapo, C. A., Oliveira, A. C. M., Leigh, M. B., \& Himelbloom, B. H. (2012). Chemical characterization of commercial liquid smoke products. Food Science \& Nutrition, 1(1), 102-115. https://doi.org/10.1002/fsn3.9

Munir, M. T., Kheirkhah, H., Baroutian, S., Quek, S. Y., \& Young, B. R. (2018). Subcritical water extraction of bioactive compounds from waste onion skin. Journal of Cleaner Production, 183, 487-494.

Nadeem, H. Ş, Torun, M., \& Özdemir, F. (2011). Spray drying of the mountain tea (Sideritis stricta) water extract by using different hydrocolloid carriers. LWT-Food Science and Technology, 44(7), $1626-1635$.

Pellicer, J. A., Fortea, M. I., Trabal, J., Rodríguez-López, M. I., Gabaldón, J. A., \& Núñez-Delicado, E. (2019). Stability of microencapsulated strawberry flavour by spray drying, freeze drying and fluid bed. Powder Technology, 347, 179-185. https://doi.org/ 10.1016/j.powtec.2019.03.010

Petzold, G., Gianelli, M. P., Bugueño, G., Celan, R., Pavez, C., \& Orellana, P. (2014). Encapsulation of liquid smoke flavoring in ca-alginate and ca-alginate-chitosan beads. Journal of Food Science and Technology, 51(1), 183-190. https://doi.org/10.1007/ s13197-013-1090-Z

Rezende, Y. R. R. S., Nogueira, J. P., \& Narain, N. (2018). Microencapsulation of extracts of bioactive compounds obtained from acerola (Malpighia emarginata DC) pulp and residue by spray and freeze drying: Chemical, morphological and chemometric characterization. Food Chemistry, 254 (November 2017), 281-291. https:// doi.org/10.1016/j.foodchem.2018.02.026

Saloko, S., Darmadji, P., Setiaji, B., \& Pranoto, Y. (2014). Antioxidative and antimicrobial activities of liquid smoke nanocapsules using chitosan and maltodextrin and its application on tuna fish preservation. Food Bioscience, 7, 71-79. https://doi.org/10.1016/j. fbio.2014.05.008

Sanchez, V., Baeza, R., Galmarini, M. V., Zamora, M. C., \& Chirife, J. (2013). Freeze-drying encapsulation of red wine polyphenols in an amorphous matrix of maltodextrin. Food and Bioprocess Technology, 6(5), 1350-1354. https://doi.org/10.1007/s11947-011-0654-z

Schranz, M., Lorber, K., Klos, K., Kerschbaumer, J., \& Buettner, A. (2017). Influence of the chemical structure on the odor qualities and odor thresholds of guaiacol-derived odorants, part 1: Alkylated, alkenylated and methoxylated derivatives. Food Chemistry, 232, 808-819.
Šimko, P. (2005). Factors affecting elimination of polycyclic aromatic hydrocarbons from smoked meat foods and liquid smoke flavorings. Molecular Nutrition and Food Research, 49(7), 637-647. https://doi.org/10.1002/mnfr.200400091

Singh, V. K., Pandey, S., Pare, A., \& Singh, R. B. (2014). Optimization of process parameters for the production of spray dried Ber (Ziziphus jujube L.) powder. Journal of food science and technology, 51(12), 3956-3962.

Soldera, S., Sebastianutto, N., \& Bortolomeazzi, R. (2008). Composition of phenolic compounds and antioxidant activity of commercial aqueous smoke flavorings. Journal of Agricultural and Food Chemistry, 56(8), 2727-2734. https://doi.org/10.1021/jf072117d

Sulaiman, C. T., \& Balachandran, I. (2012). Total phenolics and total flavonoids in selected Indian medicinal plants. Indian Journal of Pharmaceutical Sciences, 74(3), 258.

Surboyo, M. D. C., Arundina, I., Rahayu, R. P., Mansur, D., \& Bramantoro, T. (2019). Potential of distilled liquid smoke derived from coconut (Cocos nucifera L) shell for traumatic ulcer healing in diabetic rats. European Journal of Dentistry, 13(02), 271-279. https://doi.org/10. 1055/s-0039-1693527

Taruna Syah, I., Darmadji, P., \& Pranoto, Y. (2016). Microencapsulation of refined liquid smoke using maltodextrin produced from broken rice starch. Journal of Food Processing and Preservation, 40(3), 437-446. https://doi.org/10.1111/jfpp.12621

Tupuna, D. S., Paese, K., Guterres, S. S., Jablonski, A., Flôres, S. H., \& Rios, A. de O. (2018). Encapsulation efficiency and thermal stability of norbixin microencapsulated by spray-drying using different combinations of wall materials. Industrial Crops and Products, 111(December 2017), 846-855. https://doi.org/10. 1016/j.indcrop.2017.12.001

Xin, X., Bissett, A., Wang, J., Gan, A., Dell, K., \& Baroutian, S. (2021). Production of liquid smoke using fluidised-bed fast pyrolysis and its application to green lipped mussel meat. Food Control, 124, 107874. https://doi.org/10.1016/j.foodcont.2021.107874

Xin, X., Dell, K., Udugama, I. A., Young, B. R., Baroutian, S. (2020). Transforming biomass pyrolysis technologies to produce liquid smoke food flavouring. Journal of Cleaner Production, 125368. https://doi.org/10.1016/j.jclepro.2020.125368

Publisher's Note Springer Nature remains neutral with regard to jurisdictional claims in published maps and institutional affiliations. 